\title{
Molecularly Engineered “Janus GroEL”: Application to Supramolecular Copolymerization with a Higher Level of Sequence Control
}

Daiki Kashiwagi, Hao K. Shen, Seunghyun Sim, Koki Sano, Yasuhiro Ishida, Ayumi Kimura, Tatsuya Niwa, Hideki Taguchi, and Takuzo Aida J. Am. Chem. Soc., Just Accepted Manuscript • DOI: 10.1021/jacs.0c05937 • Publication Date (Web): 21 Jul 2020

Downloaded from pubs.acs.org on July 21, 2020

Just Accepted

"Just Accepted" manuscripts have been peer-reviewed and accepted for publication. They are posted online prior to technical editing, formatting for publication and author proofing. The American Chemical Society provides "Just Accepted" as a service to the research community to expedite the dissemination of scientific material as soon as possible after acceptance. "Just Accepted" manuscripts appear in full in PDF format accompanied by an HTML abstract. "Just Accepted" manuscripts have been fully peer reviewed, but should not be considered the official version of record. They are citable by the

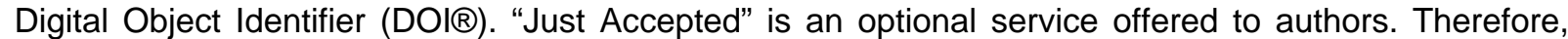
the "Just Accepted" Web site may not include all articles that will be published in the journal. After a manuscript is technically edited and formatted, it will be removed from the "Just Accepted" Web site and published as an ASAP article. Note that technical editing may introduce minor changes to the manuscript text and/or graphics which could affect content, and all legal disclaimers and ethical guidelines that apply to the journal pertain. ACS cannot be held responsible for errors or consequences arising from the use of information contained in these "Just Accepted" manuscripts. 


\title{
Molecularly Engineered "Janus GroEL": Application to Supramolec- ular Copolymerization with a Higher Level of Sequence Control
}

\author{
Daiki Kashiwagi, ${ }^{+, \perp}$ Hao K. Shen, ${ }^{+,}{ }^{\perp}$ Seunghyun Sim, ${ }^{\forall}$ Koki Sano ${ }^{\ddagger}$, Yasuhiro Ishida ${ }^{\ddagger}$, Ayumi Kimurall, Tatsuya \\ Niwa, ${ }^{\S}$ Hideki Taguchi, ${ }^{\S}$ and Takuzo Aida ${ }^{*,+, \uparrow}$ \\ ${ }^{+}$Department of Chemistry and Biotechnology, The University of Tokyo, 7-3-1 Hongo, Bunkyo-ku, Tokyo 113-8656, Japan \\ ${ }^{\forall}$ Division of Chemistry and Chemical Engineering, California Institute of Technology, Pasadena, California 91125, United States \\ " Institute of Engineering Innovation, The University of Tokyo, 2-11-16 Yayoi, Bunkyo-ku, Tokyo 113-8656, Japan \\ ${ }^{\S}$ Cell Biology Center, Institute of Innovative Research, Tokyo Institute of Technology, Midori-ku, Yokohama, 226-8503, Japan \\ ${ }^{\ddagger}$ RIKEN Center for Emergent Matter Science, 2-1 Hirosawa, Wako, Saitama 351-0198, Japan
}

\begin{abstract}
Herein, we report the synthesis and isolation of a shape-persistent Janus protein nanoparticle derived from biomolecular machine chaperonin GroEL $\left({ }^{\mathrm{A}} \mathbf{G r o E L}{ }^{\mathbf{B}}\right.$ ) and its application to DNA-mediated ternary supramolecular copolymerization. For synthesizing ${ }^{\mathrm{A}} \mathbf{G r o E L}^{\mathbf{B}}$ with two different DNA strands $\mathbf{A}$ and $\mathbf{B}$ at its opposite apical domains, we utilized the unique biological property of GroEL, i.e., " $\mathrm{Mg}^{2+} / \mathrm{ATP}-$ mediated ring exchange" between ${ }^{A} \mathbf{G r o E L} \mathbf{L}^{\mathbf{A}}$ and ${ }^{\mathbf{B}} \mathbf{G r o E L ^ { B }}$ with their hollow cylindrical double-decker architectures. This exchange event was reported more than 24 years ago but has never been utilized for molecular engineering of GroEL. We leveraged DNA nanotechnology to purely isolate Janus ${ }^{\mathbf{A}} \mathbf{G r o E L ^ { \mathbf { B } }}$ and succeeded in its precision ternary supramolecular copolymerization with two DNA comonomers $\mathbf{A}^{* *}$ and $\mathbf{B}^{*}$ that are partially complementary to $\mathbf{A}$ and $\mathbf{B}$ in ${ }^{\mathrm{A}} \mathbf{G} \mathbf{G o E L ^ { \mathrm { B } }}$, respectively, and programmed to self-dimerize on the other side. Transmission electron microscopy allowed us to confirm the formation of an expected dual-periodic copolymer sequence $-\left(\mathbf{B}^{* / B} \mathbf{G r o E L} \mathbf{L}^{\mathbf{A} / \mathbf{A}^{* *} / \mathbf{A}^{* *} / \mathbf{A}} \mathbf{G r o E L}^{\left.\mathbf{B} / \mathbf{B}^{*}\right)}\right.$ - in the form of a laterally connected lamellar assembly, rather than a single-chain copolymer.
\end{abstract}

The research field of supramolecular polymerization ${ }^{1}$ has remarkably progressed in the last two decades through a better understanding of its kinetic aspect along with the utilization of varying multivalent interactions for the connection of monomers. ${ }^{2}$ This progress allowed for a conceptual expansion of supramolecular polymerization to the development of a variety of innovative functional materials that are environmentally friendly, stimuli-responsive, self-healable, and adaptive. ${ }^{2 c}$ One of the clear advantages of supramolecular polymerization over conventional covalent polymerization is that one can use unconventional monomers. ${ }^{3}$ In 2009, we reported the supramolecular polymerization of molecular chaperone GroEL, an ATP-responsive biomolecular machine. ${ }^{3 b}$ GroEL adopts a doubledecker hollow cylindrical architecture with two heptameric rings, each comprising seven identical protein subunits. This hollow cylinder is $14.6 \mathrm{~nm}$ long with an outer diameter of $13.7 \mathrm{~nm}$, and its molecular weight is nearly $800 \mathrm{kDa}^{4}$ The biological function of GroEL is to entrap denatured proteins in its cavity and assist their refolding, in which ATP-driven mechanical motions of GroEL is known to play a vital role. ${ }^{5}$ As for its supramolecular polymerization, we reported in 2009 that GroEL with merocyanine (MC) units at its apical domain $\left({ }^{\mathbf{M C}} \mathbf{G r o E L}^{\mathrm{MC}}\right)$ serves as the monomer, and the multivalent $\mathrm{MC} / \mathrm{Mg}^{2+}$ interaction between ${ }^{\mathrm{MC}} \mathbf{G r o E L} \mathbf{L}^{\mathrm{MC}}$ gives rise to a thermally stable nanotubular polymer. ${ }^{3 \mathrm{~b}}$ Furthermore, this nanotubular polymer can serve as a tumor-specific drug carrier because it dissociates into short-chain oligomers upon treatment with ATP, which is highly concentrated due to overexpression in inflammatory (tumor) sites. ${ }^{6,7}$ Recently, we also synthesized GroELs carrying DNA strands a

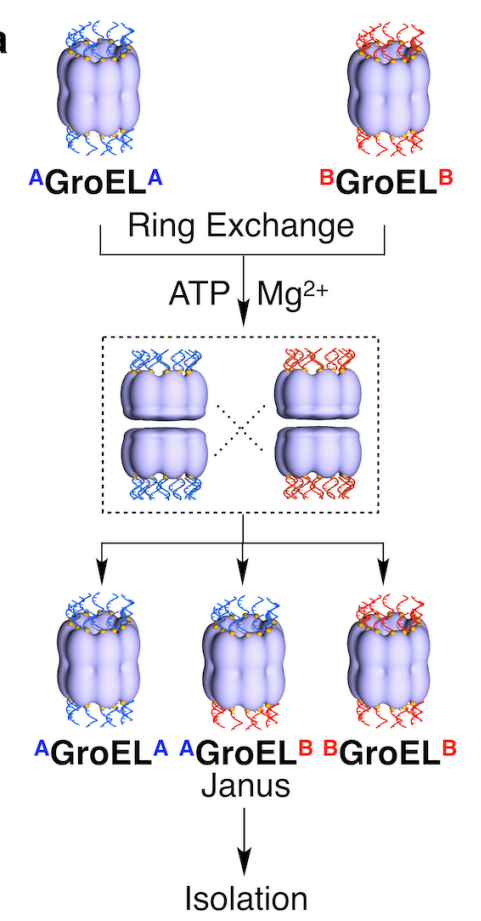

b

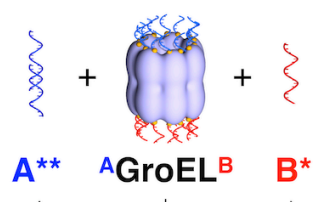

$A^{* *}$

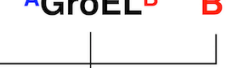

$\checkmark$

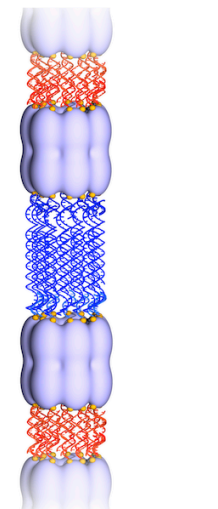

Dual-Periodic Geometry $-\left(B^{* / B} G r o E L A / A^{* *} / A^{* *} / A G r o E L B / B^{*}\right)-n$
Figure 1. Schematic representations of (a) the synthesis of DNAappended Janus GroEL ${ }^{\mathrm{A}} \mathbf{G}$ roEL $\mathbf{L}^{\mathrm{B} \text { " }}$ from a mixture of ${ }^{\mathrm{A}} \mathbf{G r o E L}^{\mathrm{A}}$ and ${ }^{\mathbf{B}} \mathbf{G r o E L}^{\mathbf{B}}$ via "ring exchange" fueled by ATP hydrolysis, and its application to (b) precision ternary supramolecular copolymerization with two DNA comonomers $\mathbf{A}^{* *}$ and $\mathbf{B}^{*}$ that are partially complementary to DNA strands $\mathbf{A}$ and $\mathbf{B}$ in ${ }^{\mathbf{A}} \mathbf{G r o E L}^{\mathbf{B}}$, respectively, and self-dimerize on the other side, with their terminal six nucleotides. The copolymer from ${ }^{\mathrm{A}} \mathbf{G r o E L}^{\mathrm{B}}$, $\mathbf{A}^{* *}$, and $\mathbf{B}^{*}$ would afford a structure with a dual-periodic sequence. For the chemical structures of $\mathbf{A}, \mathbf{B}, \mathbf{A}^{* *}$, and $\mathbf{B}^{*}$, see Table 1 . 
Table 1. List of complementary DNA pairs employed for the present study.

\begin{tabular}{|c|c|c|c|}
\hline \multicolumn{4}{|c|}{ DNA Pairs for SEC Separation and Purification } \\
\hline A/A': & 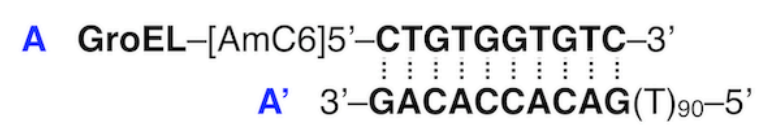 & B/B': & $\begin{array}{r}\text { B GroEL-[AmC6]5'-GCATCCTACG-3, } \\
\text { B' 3'-CGTAGGATGC (T) }{ }_{50-5},\end{array}$ \\
\hline$A^{\prime} / A^{\prime \prime}:$ & $\begin{array}{l}\text { A"-CTGTGGTGTCAAAAA-3' } \\
\text { A' 3'-GACACCACAGTTTTT }(\text { T })_{85}-5\end{array}$ & $B^{\prime} / B^{\prime \prime}:$ & $\begin{array}{l}\text { B" 5'-GCATCCTACGAAAAA-3, } \\
\text { B' 3'-CGTAGGATGCTTTTT }(T)_{45}-5,\end{array}$ \\
\hline
\end{tabular}

DNA Pairs for Ternary Supramolecular Copolymerization

A/A*/A* $\quad$ A GroEL-[AmC6]5'-CTGTGGTGTC-3'

A* 3'-GACACCACAGAAAGCCGGC-5,

A* 5'-CGGCCGAAAGACACCACAG-3'

A 3'-CTGTGGTGTC-5'[AmC6]-GroEL

$B / B^{\star} / B^{\star} / B:$

B GroEL-[AmC6]5'-GCATCCTACG-3'

B* 3'-CGTAGGATGCAAAGGCGCC-5'

B* 5'-CCGCGGAAACGTAGGATGC-3'

B 3'-GCATCCTACG-5'[AmC6]-GroEL

A/A**/A*/A: A GroEL-[AmC6]5'-CTGTGGTGTC-3'

$A^{* *}$ 3'-GCAGTTGACG-5'

A* [ 3'-GACACCACAGCGTCAACTGCAAAGCCGGC-5' 5'-GCAGTTGACG-3'

Underlined Regions: Terminal Self-Dimerization, [AmC6]: Amino C6 Linker

at their apical domains and succeeded in their binary alternating supramolecular copolymerization using the complementarity of the DNA strands. ${ }^{8}$ Such sequence-specific, supramolecular copolymers containing biomolecular machines would have a high potential for contributing to the progress of nanobiotechnology. ${ }^{9}$

In the present paper, we tackled precision ternary supramolecular copolymerization using the GroEL platform. Synthesis of ternary supramolecular copolymers with regular periodic sequences still remains a big challenge ${ }^{10}$ due to the limited number of available orthogonal connecting motifs under competitive conditions ${ }^{11}$ and an essential difficulty in visualizing copolymer sequences. ${ }^{12}$ We focused attention on a Janus GroEL carrying different DNA strands A and B at its opposite apical domains ${ }^{\mathbf{A}} \mathbf{G r o E L}^{\mathbf{B}}$. Janus protein nanoparticles have attracted significant attention for their unique dual surface functionalities useful for various applications. ${ }^{13}$ More than 24 years ago, Horwich et al. ${ }^{14 a}$ and one of us ${ }^{14 b}$ reported the formation of a Janus GroEL via $\mathrm{Mg}^{2+} / \mathrm{ATP}$-mediated ring exchange between two different GroELs, confirmed by gel electrophoresis. ${ }^{14}$ Namely, when a mixture of functionalized ${ }^{\mathbf{A}} \mathbf{G r o E L} \mathbf{L}^{\mathbf{A}}$ and ${ }^{\mathbf{B}} \mathbf{G r o E L}^{\mathbf{B}}$ is subjected to this reaction, one may generate Janus ${ }^{A} \mathbf{G r o E L}^{\mathrm{B}}$ with two rings from different origins (Figure 1a). Despite its unique geometry and potential use for nanobiotechnology, isolating a sufficient amount of Janus ${ }^{\mathrm{A}} \mathbf{G r o E L}^{\mathbf{B}}$ from the reaction mixture is inherently challenging and has been an unsolved issue. After initial struggles, we reasoned that DNA nanotechnology might be useful for this purpose. According to the procedures described in Figure 2, we successfully isolated Janus ${ }^{A} \mathbf{G r o E L}^{\mathbf{B}}$ and attempted ternary supramolecular copolymerization of ${ }^{A} \mathbf{G r o E L}^{\mathbf{B}}$ with a mixture of two DNA comonomers $\mathbf{A}^{* *}$ and $\mathbf{B}^{*}$ (Figure $1 \mathrm{~b}$ ). They are partially complementary to DNA strands $\mathbf{A}$ and $\mathbf{B}$ in ${ }^{\mathbf{A}} \mathbf{G r o E L}{ }^{\mathbf{B}}$, respectively, and are programmed to self-dimerize on the other side. As highlighted in this paper, we also succeeded in precision ternary supramolecular copolymerization with a high level of sequence control, resulting in the product of a lamellar assembly with a dual periodic sequence (Figure 4).

For the synthesis of ${ }^{\mathrm{A}} \mathbf{G r o E L}{ }^{\mathbf{B}}$, we first prepared two GroEL-DNA conjugates ${ }^{\mathbf{A}} \mathbf{G r o E L}{ }^{\mathbf{A}}$ and ${ }^{\mathbf{B}} \mathbf{G r o E L}{ }^{\mathbf{B}}$ using a cysteine-appended mutant of GroEL, CA-K311C/L314C ( ${ }^{\text {cys }}$ GroEL ${ }^{\text {cys }}$ ), carrying 14 cysteine residues at each apical domain (Table 1, see Supporting Information Method 1.2). ${ }^{8}$ The reaction mixture was subjected to SDS polyacrylamide gel electrophoresis (SDS-PAGE), which indicated that the conjugation yields with DNA strands $\mathbf{A}$ and $\mathbf{B}$ were both nearly $80 \%$ (Figure S1). Then, we attempted to generate a DNAappended Janus GroEL, ${ }^{\mathbf{A}} \mathbf{G r o E L}{ }^{\mathbf{B}}$, via ring exchange between ${ }^{\mathbf{A}} \mathbf{G r o}$ $\mathbf{E L}^{\mathbf{A}}$ and ${ }^{\mathbf{B}} \mathbf{G r o E L}^{\mathbf{B}}$ (See Supporting Information Method 1.3). Thus, a mixture of ${ }^{\mathbf{A}} \mathbf{G r o E L}^{\mathbf{A}}$ and ${ }^{\mathbf{B}} \mathbf{G r o E L}^{\mathbf{B}}(1.5 \mu \mathrm{M}$ each, $50 \mathrm{mM}$ Tris-HCl, $100 \mathrm{mM} \mathrm{KCl}, 20 \mathrm{mM} \mathrm{MgCl}_{2}, \mathrm{pH}$ 7.6) was treated with $5 \mathrm{mM}$ ATP (total volume $=52 \mu \mathrm{L}$ ) and subsequently incubated at $37^{\circ} \mathrm{C}$. After $10 \mathrm{~min}$, the reaction mixture in size exclusion chromatography (SEC) showed a single elution peak because the hydrodynamic volumes of three GroELs are similar to each other (Figure 2a). Subsequently, 30 equivalents of 100-nt DNA strand A' (Table 1), which was designed to be complementary only to DNA strand $\mathbf{A}$, was added to a mixture of ${ }^{\mathbf{A}} \mathbf{G r o E L}^{\mathbf{A}}{ }^{\mathbf{A}}{ }^{\mathbf{G r o E}} \mathbf{E L}^{\mathbf{B}}$, and ${ }^{\mathbf{B}} \mathbf{G r o E L}^{\mathbf{B}}$ (Figure 2a) in Tris buffer. The SEC profile of the reaction mixture, after being incubated at $25^{\circ} \mathrm{C}$ for $1 \mathrm{~h}$, showed three distinctive elution peaks as-

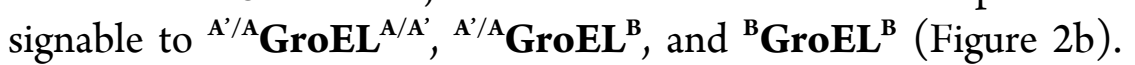
We collected a fraction containing a mixture of ${ }^{\mathbf{A}^{\prime} / \mathbf{A}} \mathbf{G r o E L}^{\mathbf{A} / \mathbf{A}^{\prime}}$ and ${ }^{\mathbf{A}^{\prime} / \mathbf{A}} \mathbf{G r o E L} \mathbf{L}^{\mathbf{B}}$ and treated it at $25^{\circ} \mathrm{C}$ with a mixture of $\mathbf{A}^{\prime \prime}$ (Table 1) [2.8 nmol], which was designed to remove $\mathbf{A}^{\prime}$ from ${ }^{\mathbf{A}^{\prime} / \mathbf{A}} \mathbf{G r o E L}^{\mathbf{A} / \mathbf{A}^{\prime}}$ and ${ }^{\mathbf{A}^{\prime} / \mathbf{A}} \mathbf{G r o E L}^{\mathbf{B}}$ via the toehold-driven DNA exchange, and $\mathbf{B}^{\prime}$ (Table 1) $[1.2 \mathrm{nmol}]$, which is a 60-nt DNA strand complementary to $\mathbf{B}$. After being incubated for $1 \mathrm{~h}$, the reaction mixture in SEC showed 


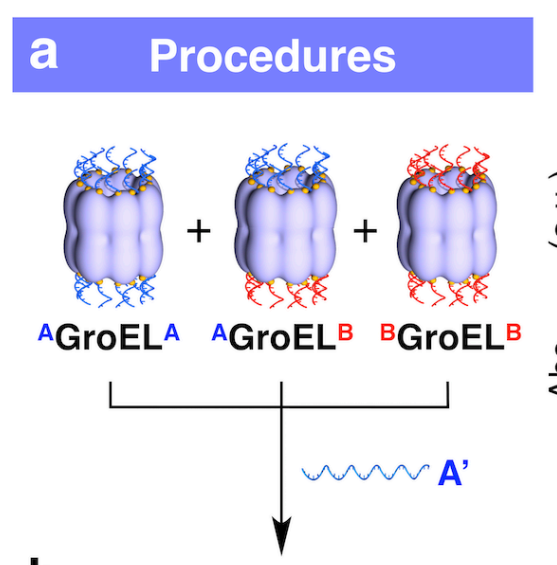

b
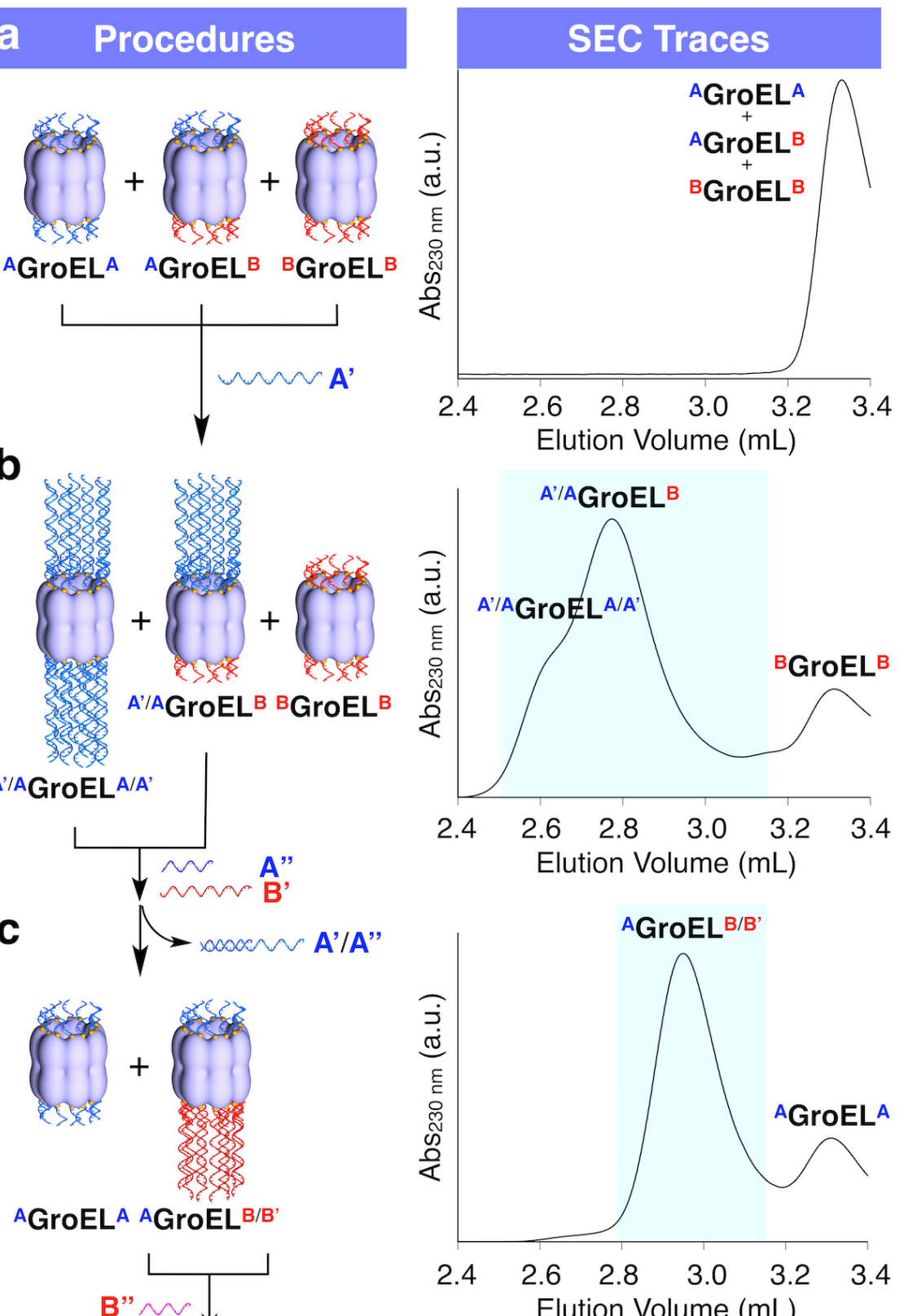

d

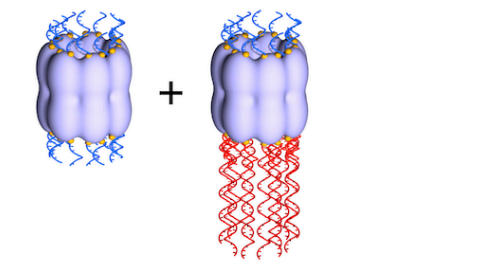

AGroELA AGroELB/B'
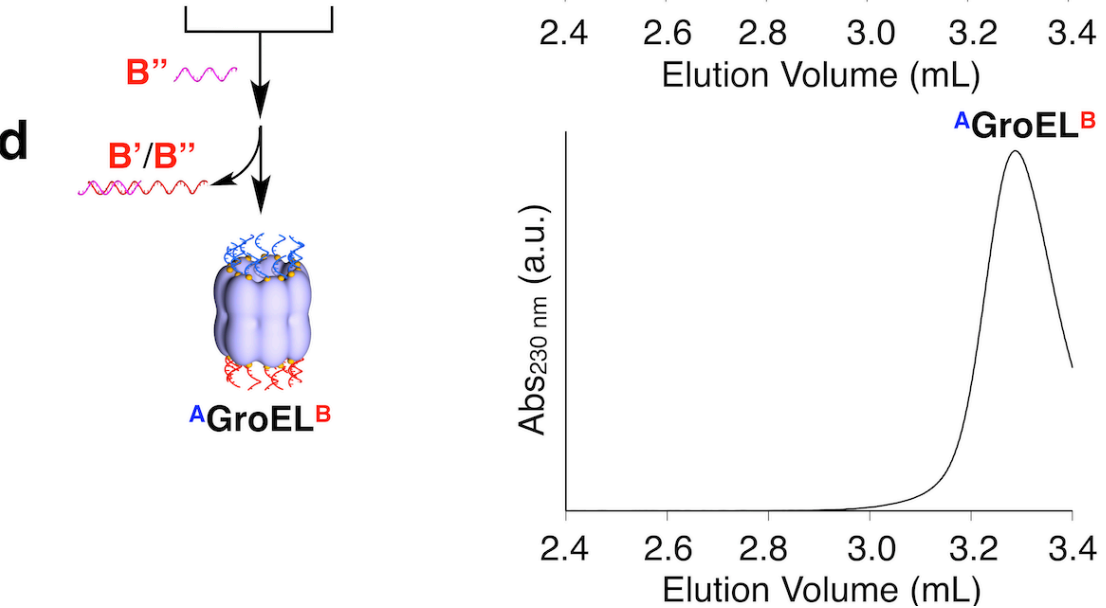

Figure 2. Schematic illustration of the isolation of DNA-appended Janus GroEL ${ }^{\mathrm{A}} \mathbf{G r o E L}^{\mathrm{B}}$, and their SEC traces of the individual steps: (a) To a mixture of ${ }^{\mathrm{A}} \mathbf{G r o E} \mathbf{L}^{\mathbf{A}}$ and ${ }^{\mathrm{B}} \mathbf{G r o E} \mathbf{L}^{\mathbf{B}}$ was added ATP to activate the ring exchange, generating Janus ${ }^{\mathrm{A}} \mathbf{G r o E} \mathbf{L}^{\mathrm{B}}$. (b) Incubation of the reaction mixture with 100-nt DNA strand $\mathbf{A}^{\prime}$, which is complementary to DNA strand $\mathbf{A}$ in ${ }^{\mathbf{A}} \mathbf{G r o E} \mathbf{L}^{\mathbf{B}}$, resulted in yielding three different hybridi-

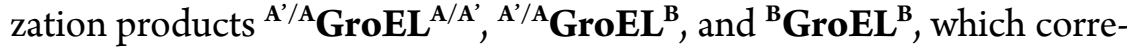
spond to three distinctive elution peaks in SEC. (c-d) A fraction con-

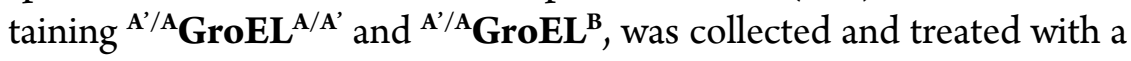
mixture of DNA strands 15-nt $\mathbf{A}^{\prime \prime}$ and 60-nt $\mathbf{B}^{\prime}$, to remove $\mathbf{A}^{\prime}$ from ${ }^{\mathbf{A}^{\prime} / \mathbf{A}} \mathbf{G r o E} \mathbf{L}^{\mathbf{A} / \mathbf{A}^{\prime}}$ and ${ }^{\mathbf{A}^{\prime} / \mathbf{A}} \mathbf{G r o E L}^{\mathbf{B}}$ and hybridize $\mathbf{B}^{\prime}$ with $\mathbf{B}$ in resultant ${ }^{\mathrm{A}} \mathbf{G r o}$ -

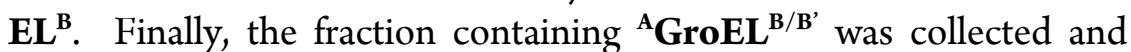
treated with 15-nt DNA strand $\mathbf{B}^{\prime \prime}$ to remove $\mathbf{B}^{\prime}$ from ${ }^{\mathbf{A}} \mathbf{G r o E L} \mathbf{L}^{\mathbf{B} / \mathbf{B}^{\prime}}$.

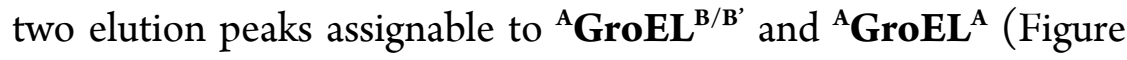
2c), where the difference in the peak elution volumes of ${ }^{\boldsymbol{A}^{\prime} / \mathbf{A}} \mathbf{G} \mathbf{r o E} \mathbf{L}^{\mathbf{B}}$ in Figure $2 b$ and ${ }^{A} \mathbf{G r o E L}^{\mathbf{B} / \mathbf{B}^{\prime}}$ in Figure $2 c$ reflects that DNA strand $\mathbf{B}^{\prime}$ is shorter by 40 -nt bases than DNA strand $\mathbf{A}^{\prime}$. We then collected a fraction containing ${ }^{\mathrm{A}} \mathbf{G r o E L ^ { \mathrm { B } / \mathbf { B } ^ { \prime } }}$ and treated it at $25^{\circ} \mathrm{C}$ with DNA
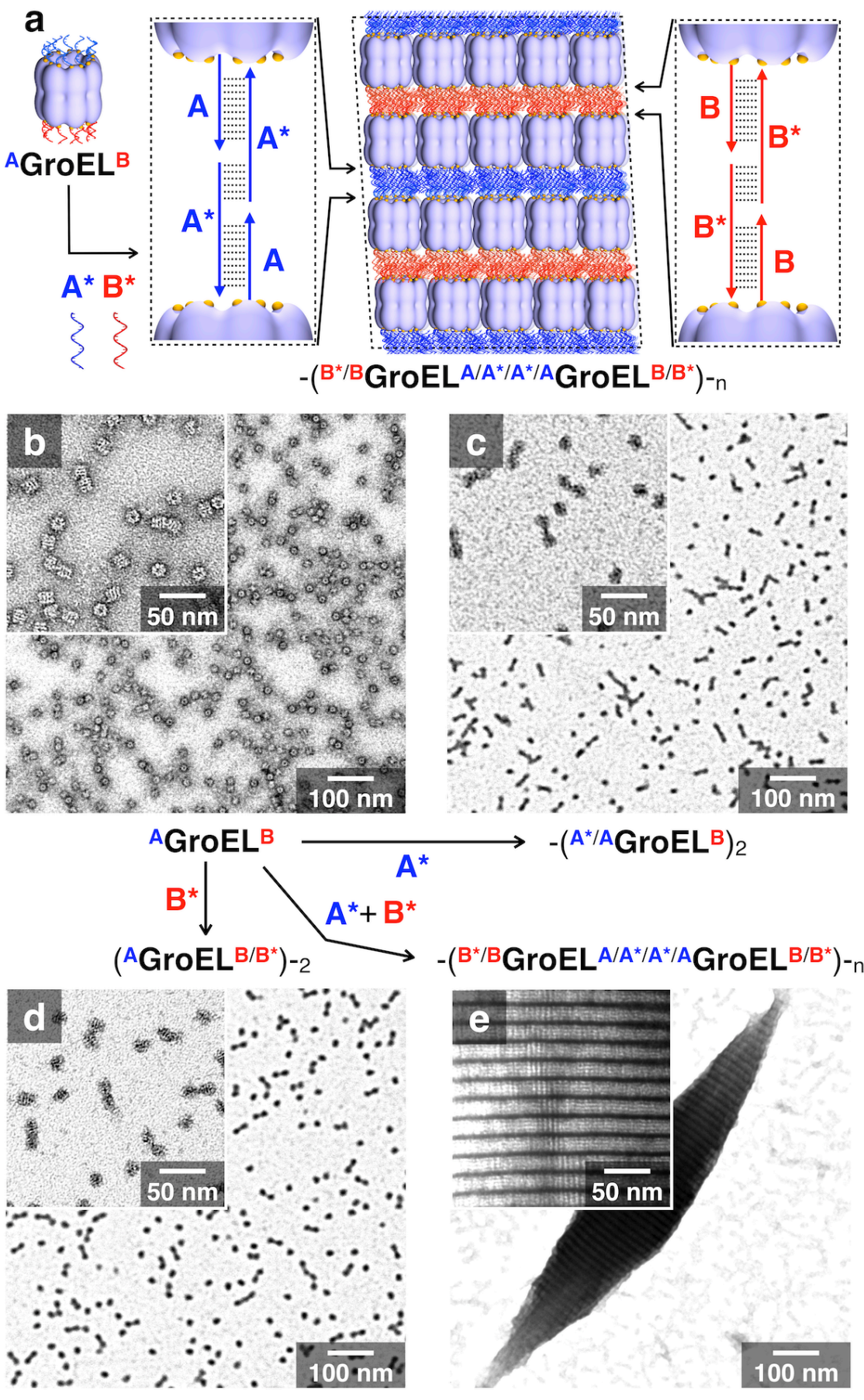

Figure 3. (a) Schematic illustration of the ternary supramolecular copolymerization of ${ }^{\mathbf{A}} \mathbf{G r o E} \mathbf{L}^{\mathbf{B}}$ with a mixture of DNA comonomers $\mathbf{A}^{*}$ and $\mathbf{B}^{*}$ (Table 1 ), yielding a regularly periodic lamellar assembly, where GroEL units are connected by DNA linkers $-\mathbf{A} / \mathbf{A}^{*} / \mathbf{A}^{*} / \mathbf{A}$ - and $\mathbf{B} / \mathbf{B}^{*} / \mathbf{B}^{*} / \mathbf{B}$-. (b-e) TEM images of $(\mathrm{b}){ }^{\mathbf{A}} \mathbf{G} \mathbf{G} \mathbf{E L}^{\mathbf{B}}$ alone, (c) a mixture of ${ }^{A} \mathbf{G r o E L} \mathbf{L}^{\mathbf{B}}$ and $\mathbf{A}^{*}$, (d) a mixture of ${ }^{\mathbf{A}} \mathbf{G r o E L ^ { B }}$ and $\mathbf{B}^{*}$, and (e) the copolymerization mixture, all stained with uranyl acetate. For the copolymerization, a mixture of ${ }^{\mathbf{A}} \mathbf{G r o E L}^{\mathbf{B}}(0.1 \mu \mathrm{M}), \mathbf{A}^{*}(10 \mu \mathrm{M})$, and $\mathbf{B}^{*}(10$ $\mu \mathrm{M})$ in Tris buffer (50 mM Tris-HCl, $100 \mathrm{mM} \mathrm{KCl}, 100 \mathrm{mM} \mathrm{MgCl}_{2}, \mathrm{pH}$ 7.6) was allowed to cool slowly from $45{ }^{\circ} \mathrm{C}$ to $20 \mathrm{C}^{\circ}$ at a rate of $0.03^{\circ} \mathrm{C} / \mathrm{min}$.

strand B” (Table 1) [1.4 nmol], which was designed to form a stable duplex with $\mathbf{B}^{\prime}$ to remove it from ${ }^{\mathbf{A}} \mathbf{G r o E L}^{\mathbf{B} / \mathbf{B}^{\prime}}$ (Figure $2 \mathrm{~d}$ ). After $1 \mathrm{~h}$, the reaction mixture showed a single elution peak due to the formation of Janus ${ }^{\mathrm{A}} \mathbf{G r o E L}^{\mathrm{B}}$, which was isolated (Figure 2d) in the total yield of $2.5 \%$ (Figure S2).

By taking advantage of the Janus architecture, ${ }^{13}$ we succeeded in precision ternary supramolecular copolymerization of ${ }^{\mathrm{A}} \mathbf{G r o E L}{ }^{\mathbf{B}}$ with two different DNA comonomers. For the copolymerization, to a Tris- $\mathrm{HCl}$ buffer solution of ${ }^{\mathrm{A}} \mathbf{G r o E L}^{\mathbf{B}}(0.1 \mu \mathrm{M}, 50 \mathrm{mM}$ Tris- $\mathrm{HCl}$, $100 \mathrm{mM} \mathrm{KCl}, 100 \mathrm{mM} \mathrm{MgCl}_{2}, \mathrm{pH}$ 7.6, Figures $3 \mathrm{~b}$ and S3) was added a mixture of DNA comonomers $\mathbf{A}^{*}$ (19-nt) and $\mathbf{B}^{*}(19-\mathrm{nt})$ that are partially complementary to DNA strands $\mathbf{A}$ and $\mathbf{B}$ in ${ }^{\mathrm{A}} \mathbf{G r o E L ^ { \mathrm { B } }}$, 
a
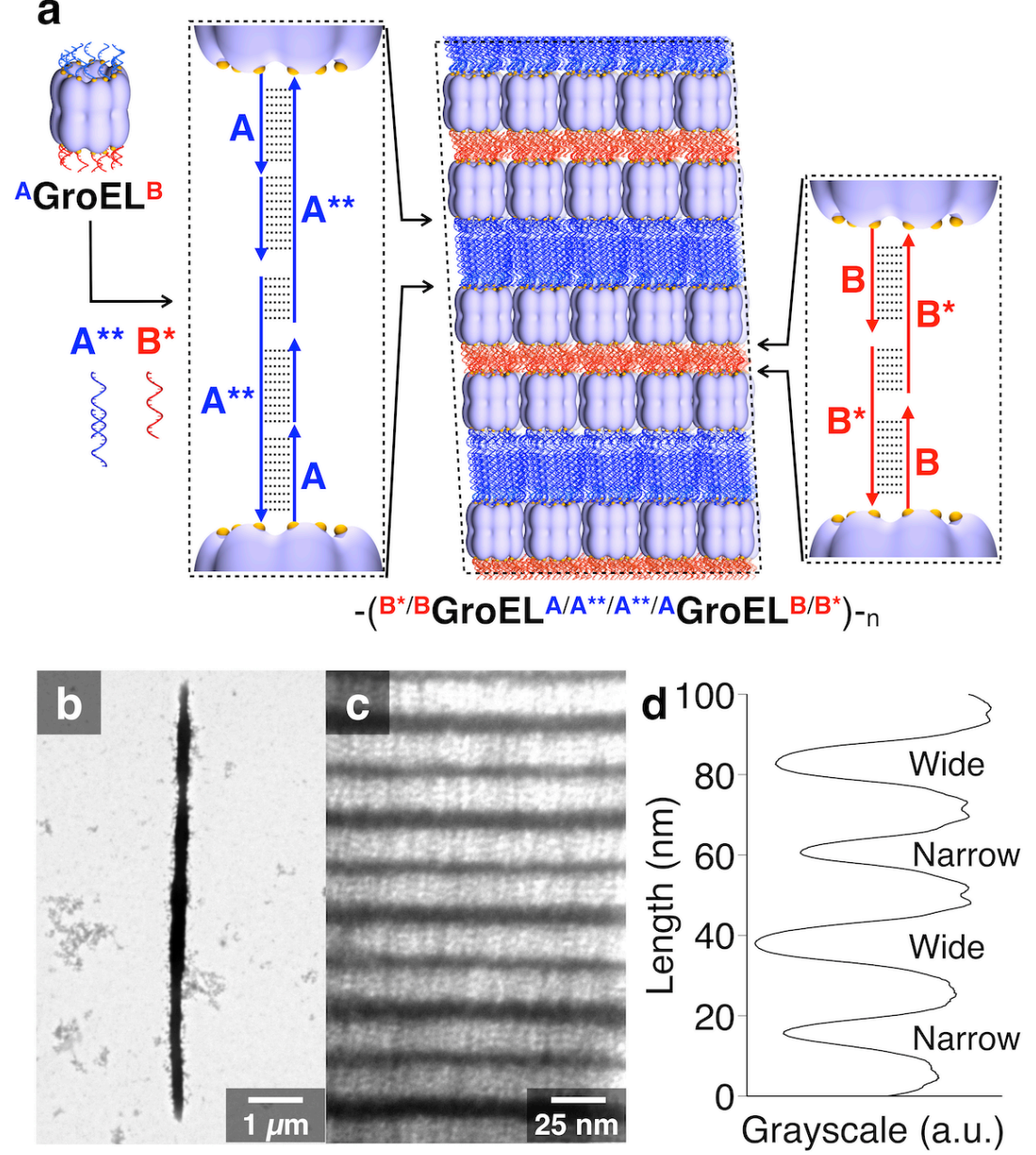

Figure 4. (a) Schematic illustration of the ternary supramolecular copolymerization of ${ }^{\mathbf{A}} \mathbf{G r o E L ^ { \mathbf { B } }}$ with a mixture of DNA comonomers $\mathbf{A}^{* *}$ and $\mathbf{B}^{*}$ (Table 1), yielding a dual-periodic lamellar assembly, where GroEL units are connected by DNA linkers $-\mathbf{A} / \mathbf{A}^{* *} / \mathbf{A}^{* *} / \mathbf{A}$ - and $\mathbf{B} / \mathbf{B}^{*} / \mathbf{B}^{*} / \mathbf{B}$ - with distinctly different lengths. (b-d) TEM images of the copolymerization mixture with (b) low and (c) high magnifications, stained with uranyl acetate, and (d) an average TEM intensity profile of the lamellar assembly. For the copolymerization, a mixture of ${ }^{\mathrm{A}} \mathbf{G r o E L}^{\mathrm{B}}$ $(0.1 \mu \mathrm{M}), \mathbf{A}^{* *}(10 \mu \mathrm{M})$, and $\mathbf{B}^{*}(10 \mu \mathrm{M})$ in Tris buffer $(50 \mathrm{mM}$ Tris$\mathrm{HCl}, 100 \mathrm{mM} \mathrm{KCl}, 100 \mathrm{mM} \mathrm{MgCl}_{2}, \mathrm{pH} 7.6$ ) was allowed to cool slowly from $45^{\circ} \mathrm{C}$ to $20 \mathrm{C}^{\circ}$ at a rate of $0.03^{\circ} \mathrm{C} / \mathrm{min}$.

respectively, but are programmed to self-dimerize at their residual terminal regions (Table 1). Subsequently, the mixture was allowed to cool slowly from $45^{\circ} \mathrm{C}$ to $20^{\circ} \mathrm{C}$ at a rate of $0.03^{\circ} \mathrm{C} / \mathrm{min}$ and subjected to transmission electron microscopy (TEM). To our surprise, what we observed was not a single-chain copolymer (Figure 1b), as reported in our previous work, ${ }^{8}$ but a periodic lamellar assembly (Figures 3e and S4). Nevertheless, together with an additional experimental result that only a short-chain oligomer (presumably a dimer) formed if either $\mathbf{A}^{*}$ or $\mathbf{B}^{*}$ was added to ${ }^{\mathbf{A}} \mathbf{G r o E L}^{\mathbf{B}}$ (Figures $3 \mathrm{c}$ and $3 \mathrm{~d}$ ), the longitudinal periodicity observed in Figure 3e suggests that the lamellar assembly comprises laterally associated copolymer

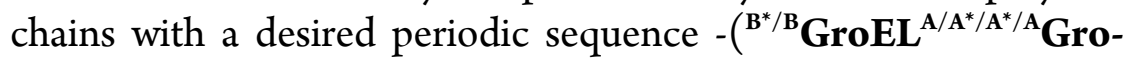
$\mathbf{E L}^{\mathbf{B} / \mathbf{B}^{*}}$ )- (Figure 3a). Judging from the magnified TEM image (Figures $3 \mathrm{e}$ ), the average width of the brighter layers is $15.0 \pm 0.6 \mathrm{~nm}$, close to the distance between two apical domains of GroEL (14.6 $\mathrm{nm}$ ). The darker layers are also uniform, with an average width of $4.8 \pm 0.4 \mathrm{~nm}$ (Figures 3e). Nevertheless, we found that even binary supramolecular copolymerization of ${ }^{\mathrm{A}} \mathbf{G} \mathbf{r o E} \mathbf{E L}^{\mathrm{A}}$ with $\mathbf{A}^{*}$ gave a lamellar assembly with a similar periodicity to that in Figure 3e (Figures S5-S7). So, at this stage, it was not evident whether the precision ternary supramolecular copolymerization with a high level of sequence control indeed took place or not.
Having such a reservation in mind, we attempted ternary supramolecular copolymerization of ${ }^{\mathbf{A}} \mathbf{G} \mathbf{O} \mathbf{E L}^{\mathbf{B}}$ with DNA comonomers $\mathbf{A}^{* *}$ and $\mathbf{B}^{*}$ (Figure $\left.4 a\right)$. Newly employed $\mathbf{A}^{* *}$ was expected to play the same role as $\mathbf{A}^{*}$, except that it consists of 2 strands forming a partial duplex structure in the middle and is distinctly longer than $\mathbf{A}^{*}$ (Table 1). Hence, if the ternary supramolecular copolymerization among ${ }^{\mathrm{A}} \mathbf{G r o E L}{ }^{\mathrm{B}}, \mathbf{A}^{* *}$, and $\mathbf{B}^{*}$ proceeds ideally with a high level of precision and likewise gives a lamellar assembly, we should observe a dual-periodic geometry ${ }^{15}$ as expected from the desired copolymer

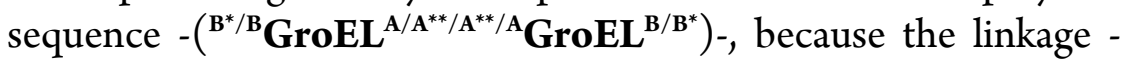
$\mathbf{A} / \mathbf{A}^{* *} / \mathbf{A}^{* *} / \mathbf{A}$ - to connect GroELs is distinctly longer than $\mathbf{B} / \mathbf{B}^{*} / \mathbf{B}^{*} / \mathbf{B}$. . The lower magnification TEM micrograph of the reaction mixture, obtained under conditions analogous to those in Figure 3 , showed the formation of several micrometer-long fibrous bundles (Figure 4b). As shown in Figure 4c, the magnified TEM image of the reaction mixture again displayed a lamellar assembly featuring the alternate appearance of brighter and darker layers originating from ${ }^{\mathrm{A}} \mathbf{G r o E L} \mathbf{L}^{\mathrm{B}}$ and DNA, respectively. As determined by the magnified TEM image, the average width of the brighter layers is $15.4 \pm$ $0.7 \mathrm{~nm}$, which is close to the distance between two apical domains of GroEL ( $14.6 \mathrm{~nm}$ ) (Figures $4 \mathrm{c}$ and $4 \mathrm{~d}$ ). Importantly, the darker layers have two different widths, $8.2 \pm 0.7 \mathrm{~nm}$ and $4.9 \pm 0.7 \mathrm{~nm}$, which appeared alternately, where the width ratio of two darker layers (1.7) is close to the ratio of the nt base numbers in two DNA linkages $\mathbf{A} / \mathbf{A}^{* *} / \mathbf{A}^{* *} / \mathbf{A}$ - and $-\mathbf{B} / \mathbf{B}^{*} / \mathbf{B}^{*} / \mathbf{B}-(1.6)$. These observations unambiguously indicate that the ternary supramolecular copolymerization product is a dual-periodic lamellar assembly with a high level of sequence control, where the non-symmetric feature of Janus ${ }^{\mathrm{A}}$ Gro$\mathbf{E L}^{\mathrm{B}}$ plays a critical role.

It should also be noted that the TEM images in both Figures $3 \mathrm{e}$ and $4 \mathrm{c}$ showed a lateral periodicity of $7.6 \mathrm{~nm}$, which is close to half the cylindrical diameter of GroEL, suggesting that the GroELs units certainly adopt an in-plane hexagonal packing (Figure S8). One more thing we should comment here is why the lamellar assembly formed, rather than single-chain copolymers. In our previous report on binary supramolecular copolymerization, ${ }^{8}$ short complementary DNA strands (10 to $15 \mathrm{nt}$ ) were directly attached to the apical domains of GroEL. In sharp contrast, the ternary supramolecular copolymers in the present study consist of two DNA bridges $\mathbf{A} / \mathbf{A}^{*} / \mathbf{A}^{*} / \mathbf{A}$ - and $-\mathbf{B} / \mathbf{B}^{*} / \mathbf{B}^{*} / \mathbf{B}$ - in Figure 3 and $-\mathbf{A} / \mathbf{A}^{* *} / \mathbf{A}^{* *} / \mathbf{A}$ and $-\mathbf{B} / \mathbf{B}^{*} / \mathbf{B}^{*} / \mathbf{B}$ - in Figure 4 , which are obviously longer than the previous case (Table 1) and presumably have a higher degree of conformational freedom. Hence, the lateral association of ${ }^{\mathrm{A}} \mathbf{G r o E L}^{\mathrm{B}}$ via non-covalent crosslinking of the DNA strands may occur concomitantly with its longitudinal connection, resulting in the bundling of adjacent copolymer chains to afford lamellar assemblies.

In summary, molecularly engineered "Janus GroEL" debuted as a new tool for nanobiotechnology, ${ }^{9,13}$ which was made possible by taking advantage of the intrinsic "ring exchange" reaction of GroEL ${ }^{14}$ together with the DNA hybridization technology. ${ }^{16}$ As described in the introductory part, sequence control in multicomponent supramolecular copolymerization, which we tackled in the present work, is one of the biggest challenges in the field of supramolecular polymerization, ${ }^{10,11,12}$ since multiple molecular interactions that orthogonally operate under competitive conditions must be properly selected. ${ }^{11}$ Furthermore, the issue of how to visualize and identify copolymer sequences is yet to be universally addressed despite rapid technological progress in related fields. ${ }^{12}$ Due to its high level of sequence control, the dual-periodic protein/DNA lamellar assembly obtained in this study was successfully characterized. ${ }^{15}$ It is 
important to note that such an ordered architecture can be precisely constructed by ternary supramolecular copolymerization, where three components are required to follow the assembling program strictly. Considering that GroEL is a biomolecular machine to induce mechanical motions in response to ATP, Janus GroEL will find its great utility as a tool for nanobiotechnology. ${ }^{6,7,17}$

\section{ASSOCIATED CONTENT}

\section{Supporting Information}

The Supporting Information is available free of charge at https://pubs.acs.org/doi/XX.XXXX/jacs.XXXXXXX

General methods, preparation and characterization of DNAappended GroELs, additional TEM images, and computed fast Fourier transform analysis of a TEM image (PDF)

\section{AUTHOR INFORMATION}

\section{Corresponding Author}

*aida@macro.t.u-tokyo.ac.jp

\section{Author Contributions}

${ }^{\perp}$ D. Kashiwagi and H. K. Shen contributed equally to this work.

\section{Notes}

The authors declare no competing financial interest.

\section{ACKNOWLEDGMENTS}

This work was supported by Grant-in-Aid for Scientific Research (S) (18H05260 to T.A.) and Nanotechnology Platform project by the Ministry of Education, Culture, Sports, Science and Technology of Japan (JPMXP09A18UT0027 and JPMXP09A20UT0042). We thank Mr. Hoshi for his assistance in transmission electron microscopy. H. K. S. thanks the scholarship of Takayama International Education Foundation. S. S. thanks Helen Hay Whitney Foundation for their support.

\section{REFERENCES}

(1) (a) Aida, T.; Takemura, A.; Fuse, M.; Inoue, S. Synthesis of a Novel Amphiphilic Porphyrin Carrying Water-Soluble Polyether Side Chains of Controlled Chain Length. Formation of a Cofacial Molecular Assembly in Aqueous Media. J. Chem. Soc. Chem. Commun. 1988, 5, 391-393. (b) Kato, T.; Fréchet, J. M. J. A New Approach to Mesophase Stabilization Through Hydrogen Bonding Molecular Interactions in Binary Mixtures. J. Am. Chem. Soc. 1989, 111, 8533-8534. (c) Fouquey, C.; Lehn, J. M.; Levelut, A. M. Molecular Recognition Directed Self-Assembly of Supramolecular Liquid Crystalline Polymers from Complementary Chiral Components. Adv. Mater. 1990, 5, 254-257. (d) Sijbesma, R. P.; Beijer, F. H.; Brunsveld, L.; Folmer, B. J. B.; Hirschberg, J. H. K. K.; Lange, R. F. M.; Lowe, J. K. L.; Meijer E. W. Reversible Polymers Formed from Self-Complementary Monomers Using Quadruple Hydrogen Bonding. Science 1997, 278, 1601-1604.

(2) (a) Aida, T.; Meijer, E. W.; Stupp, S. I. Functional Supramolecular Polymers, Science 2012, 335, 813-817. (b) Aida, T.; Meijer, E. W. Supramolecular Polymers - We've Come Full Circle. Isr. J. Chem. 2020, 60, 33-47. (c) Hashim, P. K.; Bergueiro, J.; Meijer, E. W.; Aida, T. Supramolecular Polymerization: A Conceptual Expansion for Innovative Materials. Prog. Polym. Sci. 2020, 105, 101250. (d) Wehner, M.; Würthner, F. Supramolecular Polymerization through Kinetic Pathway Control and Living Chain Growth. Nat. Rev. Chem. 2020, 4, 38-53.

(3) (a) Mirkin, C. A.; Letsinger, R. L.; Mucic, R. C.; Storhoff, J. J. A DNABased Method for Rationally Assembling Nanoparticles into Macroscopic Materials. Nature 1996, 382, 607-609. (b) Biswas, S.; Kinbara. K.; Oya, N.; Ishii, N.; Taguchi, H.; Aida, T. A Tubular Biocontainer: Metal Ion-Induced 1D Assembly of a Molecularly Engineered Chaperonin. J. Am. Chem. Soc. 2009, 131, 7556-7557. (c) Wang, Q.; Mynar, J. L.; Yoshida, M.; Lee, E.;
Lee, M.; Okuro, K.; Kinbara, K.; Aida, T. High-Water-Content Mouldable Hydrogels by Mixing Clay and a Dendritic Molecular Binder. Nature 2010, 463, 339-343. (d) Liu, M.; Ishida, Y.; Ebina, Y.; Sasaki, T.; Hikima, T.; Takata, M.; Aida, T. An Anisotropic Hydrogel with Electrostatic Repulsion between Cofacially Aligned Nanosheets. Nature 2015, 517, 68-72.

(4) (a) Xu, Z.; Horwich, A. L.; Sigler, P. B. The Crystal Structure of the Asymmetric GroEL-GroES-(ADP) 7 Chaperonin Complex. Nature 1997, 388, 741-750. (b) Takeshita, A. K.; Arakawa, T.; Taguchi, H.; Shimamura, T. Crystal Structure of a Symmetric Football-Shaped GroEL: GroES $2-\mathrm{ATP}_{14}$ Complex Determined at 3.8Å Reveals Rearrangement Between Two GroEL Rings. J. Mol. Biol. 2014, 426, 3634-3641.

(5) (a) Lorimer, G. H. GroEL Structure: A new Chapter on Assisted Folding. Structure 1994, 2, 1125-1128. (b) Taguchi, H. Chaperonin GroEL Meets the Substrate Protein as a "Load" of the Rings. J. Biochem. 2005, 137, 543-549. (c) Taguchi, H. Reaction Cycle of Chaperonin GroEL via Symmetric "Football" Intermediate. J. Mol. Biol. 2015, 427, 2912-2918.

(6) Biswas, S.; Kinbara, K.; Niwa, T.; Taguchi, H.; Ishii, N.; Watanabe, S.; Miyata, K.; Kataoka, K.; Aida, T. Biomolecular Robotics for Chemomechanically Driven Guest Delivery Fuelled by Intracellular ATP. Nat. Chem. 2013, 5, 613-620.

(7) (a) Ishii, D.; Kinbara, K.; Ishida, Y.; Ishii, N.; Okochi, M.; Yohda, M.; Aida, T. Chaperonin-Mediated Stabilization and ATP-Triggered Release of Semiconductor Nanoparticles. Nature, 2003, 423, 628-632. (b) $\mathrm{Mu}-$ ramatsu, S.; Kinbara, K.; Taguchi, H.; Ishii, N.; Aida, T. Semibiological Molecular Machine with an Implemented “AND” Logic Gate for Regulation of Protein Folding. J. Am. Chem. Soc. 2006, 128, 3764-3769. (c) Sendai, T.; Biswas, S.; Aida, T. Photoreconfigurable Supramolecular Nanotube. J. Am. Chem. Soc. 2013, 135, 11509-11512. (d) Sim, S.; Miyajima, D.; Niwa, T.; Taguchi, H.; Aida, T. Tailoring Micrometer-Long High-Integrity 1D Array of Superparamagnetic Nanoparticles in a Nanotubular Protein Jacket and its Lateral Magnetic Assembling Behavior. J. Am. Chem. Soc. 2015, 137, 4658-4661. (e) Sim, S.; Niwa, T.; Taguchi, H.; Aida, T. Supramolecular Nanotube of Chaperonin GroEL: Length Control for Cellular Uptake Using Single-ring GroEL Mutant as End-Capper. J. Am. Chem. Soc. 2016, 138, 11152-11155. (f) Sim, S.; Aida, T. Swallowing a Surgeon: Toward Clinical Nanorobots. Acc. Chem. Res. 2017, 50, 492-497.

(8) Kashiwagi, D.; Sim, S.; Niwa, T.; Taguchi, H.; Aida, T. Protein Nanotube Selectively Cleavable with DNA: Supramolecular Polymerization of “DNA-Appended Molecular Chaperones". J. Am. Chem. Soc. 2018, 140, 26-29.

(9) (a) Giljohann, D. A.; Seferos, D. S.; Daniel, W. L.; Massich, M. D.; Patel, P. C.; Mirkin, C. A. Gold Nanoparticles for Biology and Medicine. Angew. Chem. Int. Ed. 2010, 49, 3280-3294. (b) Gonen, S.; DiMaio, F.; Gonen, T.; Baker D. Design of Ordered Two-dimensional Arrays Mediated by Noncovalent Protein-Protein Interfaces. Science 2015, 348, 1365-1368. (c) Bailey, J. B.; Subramanian, R. H.; Churchfield, L. A.; Tezcan, F. A. Metal-Directed Design of Supramolecular Protein Assemblies. Method. Enzymol. 2016, 580, 223-250. (d) Sato, K.; Hendricks, M. P.; Palmer, L. C.; Stupp, S. I. Peptide Supramolecular Materials for Therapeutics. Chem. Soc. Rev. 2018, 47, 7539-7551.

(10) Adelizzi, B.; Zee, N. J. V.; de Windt, L. N. J.; Palmans, A. R. A.; Meijer, E. W. Future of Supramolecular Copolymers Unveiled by Reflecting on Covalent Copolymerization. J. Am. Chem. Soc. 2019, 141, 6110-6121.

(11) (a) Hirao, T.; Kudo, H.; Amimoto, T.; Haino, T. Sequence-Controlled Supramolecular Terpolymerization Directed by Specific Molecular Recognitions. Nat. Commn. 2017, 8, 634. (b) Wang, Q.; Chen, Y.; Liu, Y. Supramolecular Ternary Polymer Mediated by Cucurbituril and Cyclodextrin. Polym. Chem. 2013, 4, 4192-4198.

(12) (a) Albertazzi, L.; van der Zwaag, D.; Leenders, C. M. A.; Fitzner, R.; van der Hofstad, R. W.; Meijer, E. W. Probing Exchange Pathways in OneDimensional Aggregates with Super-Resolution Microscopy. Science 2014, 344, 491-495. (b) da Silva, R. M. P.; van der Zwaag, D.; Albertazzi, L.; Lee, S. S.; Meijer, E. W.; Stupp, S. I. Super-Resolution Microscopy Reveals Structural Diversity in Molecular Exchange among Peptide Amphiphile Nanofibres. Nat. Commun. 2016, 7, 11561.

(13) (a) Hayes, O. G.; McMillan, J. R.; Lee, B.; Mirkin, C. A. DNAEncoded Protein Janus Nanoparticles. J. Am. Chem. Soc. 2018, 140, 9269-9274. (b) Kang, S.; Suci, P. A.; Broomell, C. C.; Iwahori, K.; 
Kobayashi, M.; Yamashita, I.; Young, M.; Douglas, T.; Janus-Like Protein Cages. Spatially Controlled Dual-Functional Surface Modifications of Protein Cages. Nano Lett. 2009, 9, 2360-2366.

(14) (a) Burston, S. G.; Weissman, J. S.; Farr, G. W.; Fenton, W. A.; Horwich, A. L. Release of Both Native and Non-Native Proteins from a Cis-Only GroEL Ternary Complex. Nature 1996, 383, 96-99. (b) Taguchi, H.; Amada, K.; Murai, N.; Yamakoshi, M.; Yoshida, M. ATP-, K'-Dependent Heptamer Exchange Reaction Produces Hybrids between GroEL and Chaperonin from Thermus thermophilus. J. Biol. Chem. 1997, 272, 18155-18160. (c) Yan, X.; Shi, Q.; Bracher, A.; Miličić, G.; Singh, A. K.; Hartl, F. U.; HayerHartl, M. GroEL Ring Separation and Exchange in the Chaperonin Reaction. Cell 2018, 172, 605-617.

(15) (a) Ruokolainen, J.; Mảkinen, R.; Torkkeli, M; Makelä, T.; Serimaa, R.; ten Brinke, G.; Ikkala, O. Switching Supramolecular Polymeric Materials with Multiple Length Scales. Science 1998, 280, 557-560. (b) Ruokolainen, J.; ten Brinke, G.; Ikkala, O. Supramolecular Polymeric Materials with Hierarchical Structure-Within-Structure Morphologies. Adv. Mater. 1999, 11, 777-780. (c) Masuda, J.; Takano, A.; Nagata, Y.; Noro, A.; Matsushita, Y. Nanophase-Separated Synchronizing Structure with Parallel Double Periodicity from an Undecablock Terpolymer. Phys. Rev. Lett. 2006, 97, 098301. (d) Estevez, J. O.; Arriaga, J.; Reyes-Ayona, E.; Agarwal V. Chirped Dual Periodic Structures for Photonic Bloch Oscillations and Zener Tunneling. Opt. Express 2015, 23, 16500-16510. (e) Behera, S.; Joseph, J. Single-Step Optical Realization of Bio-Inspired Dual-Periodic Motheye and Gradient-IndexArray Photonic Structures. Optics Letters. 2016, 41, 3579-3582.

(16) (a) Lo, P. K.; Karam, P.; Aldaye, F. A.; McLaughlin, C. K.; Hamblin,

G. D.; Cosa, G.; Sleiman, H. F. Loading and Selective Release of Cargo in
DNA Nanotubes with Longitudinal Variation. Nat. Chem. 2010, 2, 319-328. (b) Genot, A. J.; Zhang, D. Y.; Bath, J.; Turberfield, A. J. Remote Toehold: A Mechanism for Flexible Control of DNA Hybridization Kinetics. J. Am. Chem. Soc. 2011, 133, 2177-2182. (c) Zhang, D. Y.; Seelig, G. Dynamic DNA Nanotechnology Using Strand-Displacement Reactions. Nat. Chem. 2011, 3, 103-113. (d) Seeman N. C.; Sleiman, H. F. DNA Nanotechnology, Nat. Rev. Mater. 2018, 3, 17068. (e) Rothemund P. W. K. Folding DNA to Create Nanoscale Shapes and Patterns. Nature 2006, 440, 297-302. (f) Edwardson, T. G. W.; Lau, K. L.; Bousmail, D.; Serpell, C. J.; Sleiman, H. F. Transfer of Molecular Recognition Information from DNA Nanostructures to Gold Nanoparticles. Nat. Chem. 2016, 8, 162-170. (g) Ke, Y.; Castro, C.; Choi, J. H. Structural DNA Nanotechnology: Artificial Nanostructures for Biomedical Research. Annu. Rev. Biomed. Eng. 2018, 20, 375-401.

(17) (a) Kinbara, K.; Aida, T. Toward Intelligent Molecular Machines: Directed Motions of Biological and Artificial Molecules and Assemblies. Chem. Rev. 2005, 105, 1377-1400. (b) Heuvel, M. G. L.; Dekker, C. Motor Proteins at Work for Nanotechnology. Science 2007, 317, 333-336. (c) Goel, A.; Vogel, V. Harnessing Biological Motors to Engineer Systems for Nanoscale Transport and Assembly. Nat. Nanotechnol. 2008, 3, 465-475. (d) Agarwal, A.; Hess, H. Biomolecular Motors at the Intersection of Nanotechnology and Polymer Science. Prog. Polym. Sci. 2010, 35, 252-277. (e) Jia Y.; Li, J. Molecular Assembly of Rotary and Linear Motor Proteins. Acc. Chem. Res. 2019, 52, 1623-1631. (f) Gadiel Saper and Henry Hess, Synthetic Systems Powered by Biological Molecular Motors. Chem. Rev. 2020, 120, 288-309. (g) Keya, J. J.; Kabir, A. M. R.; Kakugo, A. Synchronous Operation of Biomolecular Engines. Biophys. Rev. 2020, 12, 401-409. 
Table of Contents artwork

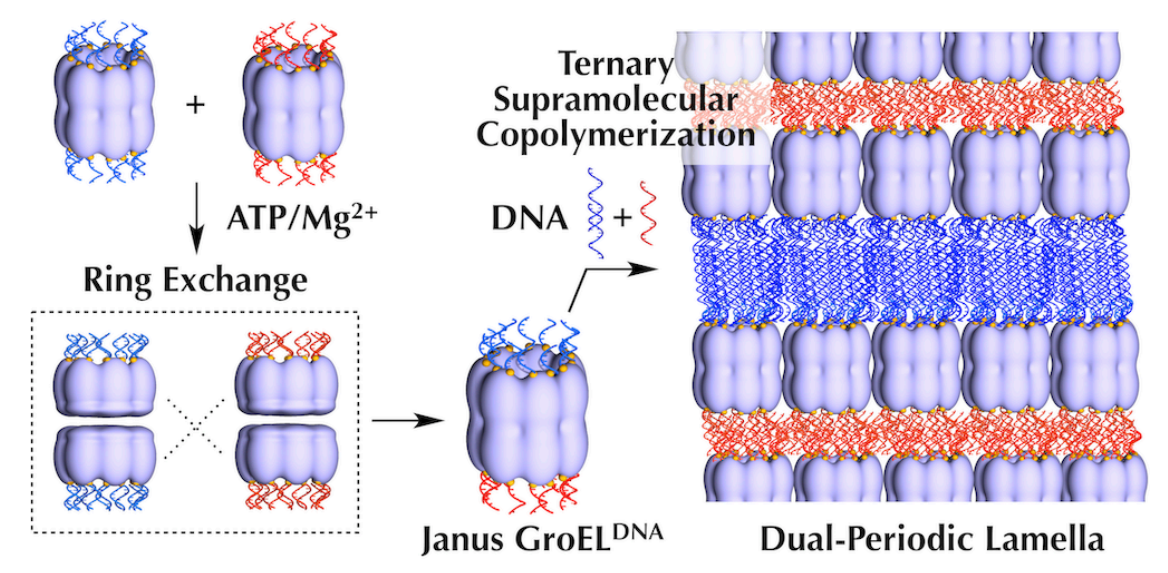

